\title{
O PLANEJAMENTO ESTRATÉGICO E O SEU PAPEL PARA A SOBREVIVÊNCIA DAS MICRO E PEQUENAS EMPRESAS
}

\section{STRATEGIC PLANNING AND ITS ROLE FOR MICRO AND SMALL BUSINESS SURVIVAL}

Matheus de Souza Lima

\begin{abstract}
Graduando em Administração da Faculdade Presidente Antônio Carlos (UNIPAC) em Aimorés - MG. E-mail: Matheus_souza_prof@hotmail.com

Charleston Sperandio de Souza Professor da Faculdade Presidente Antônio Carlos (UNIPAC) em Aimorés - MG. Administrador, Orientador, Mestre em Administração e Doutorando em Ciências Econômicas/UNLaM/Buenos Aires. E-mail: charleston.sperandio@yahoo.com.br
\end{abstract}

\section{Resumo}

Esse estudo teve como objetivo analisar a importância do planejamento estratégico nas micro e pequenas empresas. O planejamento estratégico tem como função dentro das organizações descrever as condições internas de resposta ao ambiente externo e como modificá-las, de modo a fortalecer a instituição. É uma técnica administrativa que analisa o ambiente de uma organização, criando a consistência das suas oportunidades e ameaças do ambiente de uma organização. O estudo teve critério exploratório e foi utilizado o método de pesquisa bibliográfica. Foi encontrado por meio das análises que o principal motivo para a dificuldade de surgimento de novas micro e pequenas empresas quanto para a sobrevivência das existentes é a falta de capacitação dos gestores e a falta do planejamento da organização principalmente antes da inserção do negócio no mercado e durante os dois primeiros anos de exercício. Conclui-se que o planejamento estratégico é importante e que sua utilização é fundamental para que as micro e pequenas empresas não tenham problemas futuros na sua gestão e tenham maior prosperidade no mercado.

Palavras-chave: Planejamento estratégico. Micro e pequenas empresas. Sobrevivência.

\begin{abstract}
This study aimed to analyze the importance of strategic planning in micro and small companies. Strategic planning has the function within the rules to describe as internal conditions of response to the external environment and as modifications in order to feed an instition. It is an administrative technique that analyzes the organization environment, creating the consistency of your opportunities and threats to the organization environment. The study had exploratory criteria and the bibliographic research method was used. It was found in the middle of the analysis, which is the mais reason for the difficulty of the emergence of new micro and small companies, resgarding the loss of existing capacity or the lack of capacity of managers and lack of organization planning especially before the insertion of business in the Market and during the firs two years of exercise. Conclude if strategic planning is importante and
\end{abstract}


its use is fundamental for micro and small compannies that have no future problems in their management and have greater prosperity in the market.

Keywords: Strategic planning. Micro and small businesses. Survival.

\section{Introdução}

Atualmente, as organizações estão sujeitas a constantes mudanças influenciadas pelo ambiente em que atuam. Desenvolver um planejamento estratégico torna-se um fator preponderante para viabilizar a sustentação do negócio. No mercado existem exigências do ambiente, como um atendimento personalizado que muda de acordo com o perfil do cliente, uma maior variedade de produtos e serviços, além de uma maior responsabilidade de seus gestores na hora de utilizar os recursos disponíveis, tornando imprescindível a adoção de ferramentas de gestão, buscando melhorar a eficiência e eficácia da organização.

A fundamentação teórica da pesquisa tem uma revisão na literatura, encontrado nos autores Mintezberg (2004), Chiavenato (2005), Kotler (2006), Oliveira (2007), Oliveira (2010) e Almeida e Menezes (2013), que trazem um apanhado sobre a conceitualização, a importância do planejamento estratégico e a sua aplicabilidade nas organizações.

Fischmann e Almeida (2009) conceituam o planejamento estratégico como uma técnica administrativa que cria percepção das suas oportunidades e ameaças, seus pontos fracos e fortes, de acordo com a sua missão, projetando uma direção a ser seguida para que a organização alcance seus objetivos.

É possível encontrar diversos conceitos e modelos de planejamento estratégico, porém há uma concordância entre os autores que não existe um modelo "melhor" ou "mais certo", mas existe a definição de que as organizações podem implementar um modelo em detrimento de outro de acordo com suas características.

De acordo com Bryson (1995), que apresentou um modelo a ser utilizado em organizações sem fins lucrativos, então o modelo de um plano estratégico nada mais é do que realizar as atividades de planejamento, dentro de uma concepção racional de execução, podendo ser representado por um esquema, diagrama sequencial, que indique as etapas que devem ser cumpridas de uma forma sistêmica.

De acordo com o autor citado acima, Mintezberg (2004), afirma que planejamento é um processo formalizado com a finalidade de gerar um resultado estruturado, na forma de um sistema de decisões integrada. Ainda segundo 
Mintezberg (2004), o que difere outros processos do planejamento é o seu destaque na sistematização, formalização do caso no qual se propõem aplicar o planejamento.

O objetivo geral desse estudo é analisar qual é a importância do planejamento estratégico nas micro e pequenas empresas.

\section{Referencial teórico}

O referencial teórico da presente pesquisa foi estruturado em três tópicos, a saber: definição de micro e pequena empresa; planejamento estratégico; níveis de planejamento estratégico, este contendo três subtópicos: nível estratégico; nível tático; e nível operacional; e o planejamento estratégico nas micros e pequenas empresas.

\subsection{Definição de micro e pequena empresa}

Segundo o SEBRAE (2016), existem inúmeros perfis para diferentes tipos de pequenos negócios podendo ser divididos em quatro blocos por faixa de faturamento, exceto o produtor rural pequeno. Esta segmentação segue os critérios da Lei Complementar 123/2006 que é a Lei Geral das Micro e Pequenas Empresas.

De acordo com o Sebrae (2016), as pequenas empresas são caracterizadas da seguinte maneira: micro empreendedor individual (MEI) o faturamento é de até sessenta mil reais anual; a microempresa (ME) com faturamento anual de até trezentos e sessenta mil reais; empresa de pequeno porte (EPP) com faturamento entre trezentos e sessenta mil e 3,6 milhões de reais e o pequeno produtor rural que possuir propriedade com até quatro módulos fiscais ou faturamento anual de até 3,6 milhões de reais.

\subsection{Planejamento estratégico}

O planejamento estratégico tem como função dentro das organizações de descrever as condições internas das respostas ao ambiente externo e como modificá-las, de modo a fortalecer a instituição. Dias (2015), afirma que as empresas estão em busca de se adequarem ao mercado, mas em algumas ocasiões para isso, é necessário reduzir o número de pessoal ou até mesmo do preço de venda. Mas, com a tendência de automatização dos processos é favorável às empresas, uma vez que a produtividade tende a aumentar, já que esse processo tende a aumentar a qualidade de vida dos associados durante a execução do trabalho. 
Planejamento Estratégico é uma técnica administrativa que analisa 0 ambiente de uma organização, criando a consistência das suas oportunidades e ameaças do ambiente de uma organização (FISCHIMANN, 2009).

Segundo Oliveira (2007), o planejamento estratégico se descreve como um processo no setor administrativo que proporciona sustentação metodológica para se estabelecer a melhor direção a ser seguida pela organização, com o intuito de otimizar a interação com os fatores externos não influenciáveis, atuando de forma inovadora e diferenciada.

Oliveira (2007) ainda afirma que o planejamento estratégico geralmente fica sob responsabilidade dos mais altos níveis dentro de uma organização, e diz respeito tanto à criação de objetos quanto à seleção dos cursos de ação a serem seguidas para alcançar os objetivos almejados, considerando o ambiente externo e interno à organização e sua evolução esperada.

Almeida e Menezes (2013), afirmam que com a implantação de um planejamento estratégico é possível observar algumas vantagens, sendo elas: um maior alinhamento da organização, possibilidade de aprimoramento no conhecimento sobre os clientes e concorrentes, os colaboradores passam a ter um maior comprometimento a atingir os objetivos da organização e também há possibilidades de aumentar a eficiência na tomada de decisões, deixando claros os motivos pelas quais as organizações passaram a aderir essa estratégia.

Por se tratar de uma ferramenta importante em que as ações tomadas causam e irão causar impactos dentro da organização, são dos níveis mais altos a responsabilidade de iniciar a elaboração do planejamento estratégico, sendo necessário considerar todas as condições existenciais da organização, tanto internas quanto externas na sua elaboração, respeitando sempre os limites da própria organização e do que é objetivado a alcançar (ALMEIDA; MENEZES, 2013).

Para Kotler (2006), o planejamento estratégico trata-se de uma metodologia de gerenciamento que permite os gestores estabelecer para a organização qual a melhor direção a ser seguida, sempre visando a melhoria no grau de interação com o ambiente. A direção escolhida pela organização engloba as questões de macro política, macro estratégias e os objetivos funcionais. Já em relação à interação de organização/ambiente, esta pode variar de acordo como o alinhamento dos objetivos traçados pela organização, essa pode ser positiva, neutra ou negativa. 
Para Kotler (1992), o planejamento estratégico é o processo gerencial de desenvolver e manter uma adequação razoável entre os objetivos e recursos da organização e de monitorar o mercado e suas mudanças.

Sobre o valor do planejamento estratégico como ferramenta de auxílio a alta administração, Barbosa e Brondani (2005) afirmam que o planejamento estratégico é uma valiosa ferramenta de auxílio à alta administração, por permitir que as organizações dêem direções as ações gerenciais dentro de um plano previamente determinado de metas e estratégias, com isso, diminuindo a possibilidade de tomada de decisões equivocadas, num mercado que extremamente competitivo e que não permite erro.

\subsubsection{Níveis de planejamento estratégico}

O planejamento estratégico é dividido em três níveis, sendo eles: estratégico, tático ou gerencial e operacional.

Oliveira (2010, p. 87), demonstra os três níveis de planejamento estratégico em forma de pirâmide, conforme figura1 abaixo.

Figura 1 - Níveis de planejamento estratégico.

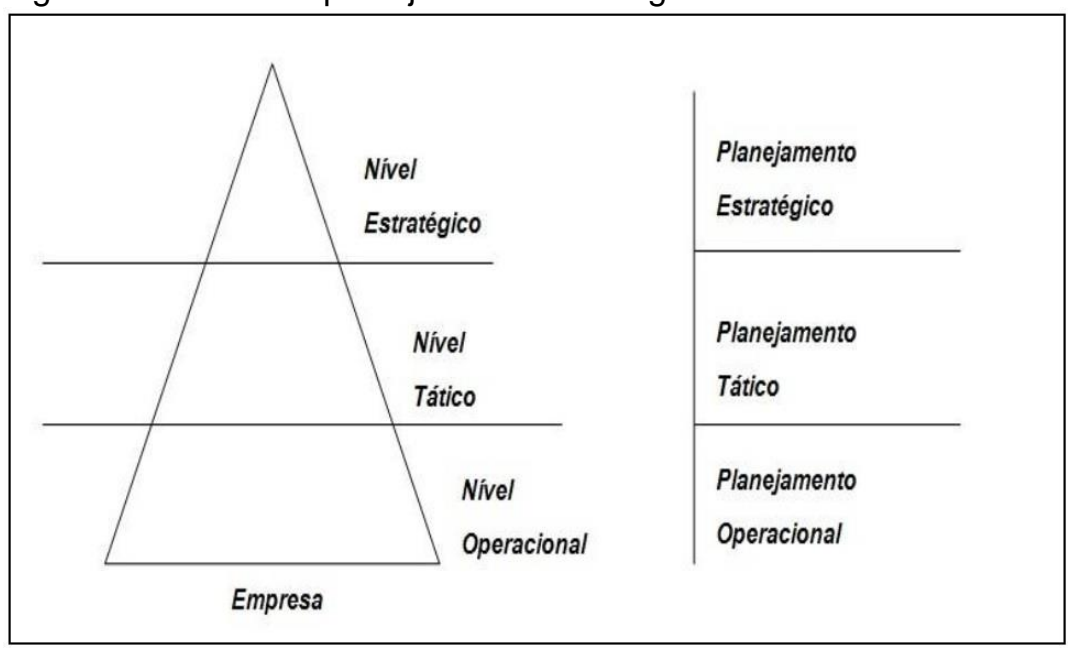

Fonte: OLIVEIRA (2010, p. 87).

Para Oliveira (2010), o nível estratégico permite ao empreendedor estabelecer uma direção a ser seguida pela organização. O nível tático é definido pela alta gestão e é mais específico à alguma área da organização, tendo o intuito de obter melhora nos resultados. O nível operacional é onde as ações traçadas nos níveis anteriores da pirâmide são desempenhadas. Nesse nível atuam os envolvidos que executam as ações que são realizadas em curto prazo, geralmente com duração de três a seis meses. 


\subsubsection{Nível estratégico}

Segundo Oliveira (2009a), o planejamento estratégico se dá por uma metodologia que apresenta cenários de possibilidades e direções possíveis e permite que a organização estabeleça uma direção e a auxilia no desenvolvimento de suas estratégias.

Para Almeida (2001), o planejamento estratégico se define por uma técnica administrativa que procura ordenar as ideias de pessoas, de forma que possa ser criada uma visão do caminho que se deve seguir (estratégia). Depois disso, são ordenadas as ações, que é a implementação do Plano Estratégico, para que, sem desperdício de esforços, consiga se caminhar na direção pretendida.

De acordo com Padoveze (2003, p.96),

Um plano estratégico é uma visão específica do futuro da empresa, que contém as seguintes descrições:

- Como será o setor de atuação da empresa;

- Quais os mercados que ela irá competir;

- Quais produtos e serviços a empresa oferecerá;

- Quem é e como são os seus clientes;

- Que valor oferecerá a seus clientes através de seus produtos e serviços;

- Quais vantagens ele terá no longo prazo;

- Qual será ou deverá ser o seu porte;

- Qual será o deverá ser a sua rentabilidade; e;

- Quanto será agregado de valor aos acionistas.

Oliveira (2002) ainda ressalta que o planejamento estratégico apresenta as possibilidades de como definir e estruturar as ações, a fim de alcançar os resultados definidos pela organização.

\subsubsection{Nível tático}

Segundo Oliveira (2002), o planejamento tático tem como objetivo aperfeiçoar determinada área de resultado e não a empresa como um todo.

Oliveira (2009) conceitua o planejamento tático como uma metodologia administrava que possui o objetivo de aperfeiçoar o resultado de determinada área/setor da organização, que visa uma situação desejada no futuro.

Para Andrade (2012), todos os departamentos da organização estão abrangidos pelo planejamento tático, estando focado para a realização em médio 
prazo. O administrador utiliza desta ferramenta para conseguir o que a maioria das organizações procura alcançar com o sucesso das metas dentro do período estimado, que é desenvolvimento nas áreas de produção, marketing, pessoal, finanças e contábil.

\subsubsection{Nível operacional}

Seguindo Chiavenato (2005), o planejamento operacional foca no curto prazo abrangendo todas as tarefas ou operações individualmente. Empenha-se em "o que fazer" e com o "como fazer" as atividades do cotidiano da organização. Refere-se apenas às tarefas e operações realizadas à nível operacional.

Para Oliveira (2002), o planejamento operacional é a formalização de documentos escritos, que se inicia nas metodologias do desenvolvimento e se estende até as implantações formadas, assim, nesta colocação é possível obter os planos de ação ou planos operacionais. Oliveira (2012) salienta ainda que, é de responsabilidade dos níveis inferiores das organizações a realização das atividades rotineiras.

$\mathrm{Na}$ visão de Sertek; Guindani; Martin (2011), o nível operacional é o responsável pela execução das tarefas; as pessoas são quem fabricam os produtos e que também possuem uma ligação direta com os clientes. Exemplo: auxiliares, secretárias, telemarketing, vendedores etc.

\subsection{O Planejamento Estratégico nas Micros e Pequenas Empresas}

Quando se fala em pequenas empresas não significa pensar na ideia de ser frágil. Temos inúmeros exemplos no mercado que empresa fragilizada não é necessariamente sinônimo de ser empresa pequena. Uma empresa ser pequena não tem a ver com fragilidade ou falta de competência (MALHEIROS et al., 2005).

A competição entre as empresas se dá pela capacidade de gerar inovações continuamente. O segredo do sucesso para as pequenas e médias empresas é, definir metas. A definição de metas tornará mais claro para os empresários de pequeno e médio porte os objetivos da sua organização (NEUMAM, 2013).

$\mathrm{O}$ crescimento das micro e pequenas empresas são cada vez mais notado no Brasil e as organizações devem-se planejar a organizar, porém, é primordial a prática para que se obtenha resultados e não ficar somente na teoria. (KASSAI, 1997). 
Os profissionais responsáveis pela gestão das micro e pequenas empresas, condizem em geral às tomadas de decisões das organizações de forma empírica, isso ocorre em sua grande maioria por falta de preparo dos profissionais, muitas das vezes essas decisões se baseiam em preocupações de curto prazo dos sócios proprietários da empresa. Com uma gestão voltada para a qualidade integral e eficiência, as decisões devem ser tomadas seguindo um procedimento objetivando garantir o conhecimento das melhores ou possíveis opções, missão que corresponda e atenda por um eficiente programa de planejamento estratégico (SOUZA; QUALHARINI, 2007).

Segundo Chér (1990), o surgimento de problemas administrativos inibidores da eficiência pode ser causado pela inexistência de uma clara definição de cargos e tarefas, por exemplo, nas micro e pequenas empresas. As queixas de pequenos e médios empresários de que o trabalho dentro da empresa é mal dividido, inexistindo critérios para as atividades funcionais é cada vez mais normal.

Malheiros et al. (2005) dizem que apenas sobreviverão as empresas que são capazes de se adaptar rapidamente às transformações e exigências do mercado. $A$ tomada de decisões precisa ser rápida, precisa e descentralizada. Hoje, ser pequeno é uma grande solução, mas para isso, apenas uma boa formação acadêmica já não é o suficiente. $O$ mercado exige que os gestores busquem o aprendizado constante, a busca contínua de nível de capacitação profissional para que haja uma boa gestão da pequena empresa.

De acordo com Grapeggia et al. (2011) existem inúmeros casos de micro ou pequenas empresas que fecham nos primeiros anos após o início das suas atividades. Muitos culpam a crise do país, já outros consideram a falta de recurso como principal causa, mas em sua grande maioria não se preocupam em planejar antes de abrir o negócio e durante a atividade.

Segundo dados do Sebrae (2016), entre 2010 e 2014 passou de 54\% para $77 \%$ a taxa de sobrevivência das empresas com até dois anos. Muito desse crescimento se deve à ampliação do número de Micro empreendedores Individuais (MEI). Quando estes são excluídos da análise, a taxa de sobrevivência cresce de $54 \%$ para $58 \%$ apenas. O impacto positivo causado pelo MEI nessa análise da taxa de sobrevivência de empresas sedeve pela alta taxa desse segmento, a participação no total de empreendimentos passou de $0 \%$ em 2008, para $63 \%$ em 2012 do total de novas empresas. 
De acordo com o Sebrae (2011), mais da metade dos empregos com carteira assinada no Brasil são geradas por micro e pequenas empresas. A sobrevivência dessas organizações é fundamental para o crescimento econômico do país e vários estudos identificam que os dois primeiros anos de exercício de uma nova empresa são os mais exigentes, o que torna essa fase essencial para o acompanhamento da sobrevivência.

Junior e Pisa (2010) comentam que as ideias para os empreendimentos devem ser utilizadas para que a taxa de mortalidade das micro e pequenas empresas não seja uma realidade tão normal. A identificação das necessidades da organização é observar as deficiências e tendências do ambiente em que ela se encontra são uma delas.

Junio e Pisa (2010) ainda completam que, essas necessidades, somente uma pessoa que tem capacidade de planejar e administrar, ou seja, que é empreendedora irá conseguir fazer com que a micro e pequena empresa não feche.

Por fim, é preciso que tanto as deficiências quanto as tendências estejam em observações para que a micro e pequena empresa vá adiante, pois são por meio das observações que poderá ser colocado em prática as melhores estratégias de gestão e administração.

\section{Metodologia}

Para a realização desse estudo, quanto aos objetivos, foi utilizada a pesquisa exploratória. Gil (2008) define que pesquisa exploratória proporciona uma maior familiaridade com o problema, ou seja, explicitá-lo. Podendo envolver entrevistas com pessoas com conhecimento no problema pesquisado ou levantamento bibliográfico.

Quanto ao método utilizado na pesquisa, tratou-se de uma pesquisa bibliográfica. Segundo Gil (2008), a pesquisa bibliográfica é desenvolvida embasada em materiais já elaborados, extraídos em sua grande parte de livros e artigos científicos.

Quanto à abordagem do problema, a pesquisa a ser utilizada é a pesquisa qualitativa, que na visão de Guth e Pinto (2007) trata-se de uma ferramenta útil para determinar o que e porque é importante para os indivíduos. 


\section{Discussão}

De acordo com o levantamento bibliográfico realizado na pesquisa, as micro e pequenas empresas são responsáveis por 63\% das novas empresas iniciadas em 2012 e também são as maiores geradoras de emprego no país, e pode-se afirmar que as grandes dificuldades encontradas pelas micro e pequenas empresas para se inserirem e sobreviverem no mercado atualmente de forma consolidada se dá pela falta de capacitação dos empresários que geralmente tomam as decisões de forma empírica e do não planejamento antes da abertura do negócio e durante o seu amadurecimento no mercado.

\section{Considerações finais}

O objetivo geral da pesquisa foi analisar qual a importância do planejamento estratégico nas micro e pequenas empresas, e o mesmo foi alcançado por entender que o planejamento estratégico é fundamental para as micros e pequenas empresas tanto na fase de implantação no mercado, quanto na fase de amadurecimento.

Pertinente destacar que o gestor deve possuir capacitação técnica da atividade fim de atuação da empresa, sobre a gestão e sobre o mercado em que a organização quer se inserir ou se encontra inserida para que as tomadas de decisões não sejam tomadas de forma empírica e sim consistentes, com a garantia de possuir o conhecimento das melhores ou possíveis opções, atendendo por um eficiente programa de planejamento estratégico.

Por fim, recomenda-se que o presente estudo seja dado continuidade para revelar novos resultados ou confirmar os achados por esse.

\section{Referências}

ALMEIDA, A. A.; MENEZES, J. F. A importância do planejamento estratégico como fator preponderante ao crescimento organizacional. Lagarto: revista eletrônica, setembro de 2013, nº 8, p. 60-76.

ALMEIDA, Martinho Isnard Ribeiro de. Manual de planejamento estratégico: desenvolvimento de um plano estratégico com utilização de planilhas Excel. $1^{\circ}$ ed. São Paulo: Atlas, 2001.

ANDRADE, Arnaldo Rosa de. Planejamento Estratégico: formulação, implementação e controle. $1^{\circ}$ ed. São Paulo: Atlas, 2012. 
BARBOSA, E. R.; BRONDANI, G. Planejamento estratégico organizacional. Revista Eletrônica de Contabilidade. São Paulo, v. 1, n. 2, p. 107-123, 2005.

BRYSON, J.M. Strategic planning for public and nonprofit organizations. San Francisco: Jossey Bass, 325 p. 1995.

CHÉR, Rogério. A gerência das pequenas e médias empresas: o que saber para administrá-las. São Paulo. Editora Maltese, 1990.

CHIAVENATO, Idalberto. Administração nos novos tempos. $2^{\circ}$ ed. Revista e atualizada, Rio de Janeiro: Campus, 2005.

FISCHIMANN, A. A.; ALMEIDA, Martinho, I. R. Planejamento estratégico na prática. 2. ed. São Paulo: Atlas, 1991.

Planejamento estratégico na prática / Adalberto A. Fischimann, Martinho Isnard Ribeiro de Almeida: São Paulo, 2 ed., 14 reimpr.: Atlas 2009.

GIL, Antonio Carlos. Como elaborar projetos de pesquisa. 4. Ed. São Paulo: Atlas, 2008.

GRAPEGGIA, M; LEZANA, A. G. R.; ORTIGARA, A. A.; SANTOS, P. C. F. Fatores condicionantes de sucesso e/ou mortalidade de micro e pequenas empresas em Santa Catarina. 2011. Disponível em:

$<$ http://www.scielo.br/scielo.php?script=sci_arttext\&pid=S0103-

65132011000300008>. Acesso em: 06/12/2019.

GUTH, Sérgio Cavagnoli; PINTO, Marco Moreira. Desmistificando a produção de textos científicos com os fundamentos da metodologia científica. São Paulo: Scortecci, 2007.

JUNIOR, A. B. L.; PISA, B. J. Administrando o micro e pequenas empresas. Rio de Janeiro: Rio de Janeiro, 2010.

KASSAI, Silvia. As empresas de pequeno porte e a contabilidade. Cad. Estud. No. 15. São Paulo, 1997. Disponível em: < http://www.scielo.br/scielo.php?pid=S1413-92511997000100004\&script=sci_arttext>. Acesso em 06/12/2019.

KLEIN, Jefferson. Abicalçados revê previsão e espera crescimento maior. Jornal do Comércio. 25/09/2019. Disponível em:

<https://www.jornaldocomercio.com/_conteudo/economia/2019/09/704402abicalcados-reve-previsao-e-espera-crescimento-maior.html>. Acesso em: 21/11/2019.

KOTLER, Philip. Administração de marketing: análise, planejamento, implementação e controle. 2. Ed. São Paulo: Editoriais Atlas, 1992. P. 63.

Administração de marketing: análise, planejamento, implementação e controle. 4. Ed. São Paulo, Pearson, 2006. 
MALHEIROS, Rita de Cássia da Costa. FERLA, Luiz Alberto. CUNHA, Cristiano J. C. de Almeida. Viagem ao Mundo do Empreendedorismo. Florianópolis: IEA Instituto de Estudos Avançados. 2ํㅡㄹㄷão, 2005.

MINTZBERG, Henry. Ascensão e queda do planejamento estratégico. Porto Alegre: Bookman Editora, 2004.

NEUMAN, C. 2013. Gestão de sistemas de produção e operações: produtividade, lucratividade e competitividade. Disponível em:

<https://books.google.com.br/books?id=tSxHAAAAQBAJ\&pg=PT22\&dq=Defini\%C3 $\%$ A7\%C3\%A3o+de+metas+para+pequenas+e+m\%C3\%A9dias+empresas\&hl=ptBR\&sa $=$ X\&ved=0ahUKEwjggOHEh9fLAhXEIJAKHbzsCX0Q6AEILjAC\#v=onepage\& q=Defini\%C3\%A7\%C3\%A30\%20de\%20metas\%20para\%20pequenas\%20e\%20m\% C3\%A9dias\%20empresas\&f=false $>$. Acesso em 06/12/2019.

OLIVEIRA, Djalma de Pinho Rebouças de. Planejamento estratégico: conceitos, metodologia e práticas. São Paulo: Atlas, 2007. Atlas, 2012.

Planejamento estratégico: conceitos, metodologia, práticas. São Paulo:

Planejamento estratégico: conceitos, metodologia e práticas. 22.ed. São Paulo: Atlas, 2005.

Administração estratégica na prática: A competitividade para administrar o futuro das empresas. 6ํe ed. São Paulo: Atlas, 2009a.

Planejamento estratégico: conceitos, metodologia e práticas. $17^{\circ}$ ed. São Paulo: Atlas, 2002.

Sistemas, organizações \& métodos: uma abordagem gerencial. 19. Ed. São Paulo: Atlas, 2010.

PADOVEZE, Clóvis Luís. Controladoria, estratégica e operacional: conceitos, estrutura e aplicação. São Paulo: Thonson, 2003.

SEBRAE. Quem são os pequenos negócios? Estudos e pesquisa. 2016. Disponível em:

$<$ http://www.sebrae.com.br/sites/PortalSebrae/estudos_pesquisas/Quems\%C3\%A3o-os-pequenos-neg\%C3\%B3cios\%3F,destaque,5>. Acesso em 06/12/2019.

Sobrevivência das empresas no Brasil. 2016. Disponível em: <http://datasebrae.com.br/sobrevivencia-das-empresas/>. Acesso em 06/12/2019.

. Taxa de sobrevivência das empresas no Brasil. 2011. Disponível em: <http://www.sebrae.com.br/Sebrae/Portal\%20Sebrae/Anexos/Sobrevivencia_das_e mpresas_no_Brasil_2011.pdf>. Acesso em 06/12/2019. 
SERTEK, Paulo; GUINDANI, Roberto Ari; MARTINS, Tomás Sparano.

Administração e planejamento estratégico. 3. Ed. Curitiba: IBPEX, 2011.

SOUZA, Wendel. QUALHARINI, E. O planejamento estratégico nas micro e pequenas empresas. Anais do III Workshop Gestão Integrada: Riscos e Desafios. Centro Universitário SENPC. São Paulo, 2007. 